\title{
Patterns of psychiatry morbidity in referred patients attending psychiatry out patient department in a tertiary centre
}

\section{Malla DP', Basnet RS'2, Pokharel $\mathrm{AM}^{3}$}

'Deep Prakash Malla, Lecturer; ${ }^{2}$ Rachana Sharma Basnet, Lecturer; Department of Psychiatry, ${ }^{3}$ Aakriti Malla Pokharel, Lecturer; Department of Community Medicine, Kathmandu Medical College Teaching Hospital, Kathmandu, Nepal

\begin{abstract}
Background: Consultation-liaison psychiatry is an important part of psychiatry dealing with cases having co morbid general medical conditions. Psychiatrists need to be involved in evaluation of patients referred from other specialties. Objectives: To assess the patterns of psychiatry morbidity in referred patients attending psychiatry out patient department of Kathmandu Medical College.

Methods: A total of 200 patients were referred to the department of psychiatry from different out patient departments during a period of six months. Each of them underwent a detailed psychiatric evaluation.

Results: The mean age of the patients evaluated was 36.03 years; most of them were females (66.5\%), married (67\%), educated up to class seven (28\%) and housewives (32.5\%) living in a nuclear family (62.5\%) coming from a middle income socio-economic status (75\%). More than half (52\%) referrals were from Medical ward coming with the chief complaint of headache (18.5\%) followed by disturbance in sleep pattern (17\%) and pain in more than three sites (17\%). The most common psychiatric diagnosis was depression (49\%) followed by anxiety (35.5\%). A majority of the patients (55\%) perceived their illness to be neurological and had received alternative treatment from a faith healer (26\%) before being referred to the psychiatric out patient department.

Conclusion: Psychiatric consultation was sought mostly by medical out patient department that had maximum number of patients. The commonest diagnosis seen in the referred out-patients was depression and anxiety disorder. Patients mostly presented with vague somatic complaints such as headache, disturbance in sleep pattern and pain over more than three sites of the body.
\end{abstract}

Key words: Consultation liaison, Psychiatric morbidity, Psychiatric referral

\section{INTRODUCTION}

VTHO defines health as a state of complete physical, mental and social well-being and not merely the absence of disease or infirmity ${ }^{1}$. Hence, health includes mental, physical and social functioning, which are closely associated and interdependent. There is evidence that mental and physical illnesses may accompany, follow or precede one another as well as evidence indicating that mental disorders increase the risk of physical illness and vice versa'. There are also interrelationships between mental and physical health. For example, cardiovascular disease can lead to depression and vice versa. Mental

Address for correspondence

Dr. Deep Prakash Malla

Lecturer, Department of Psychiatry

Kathmandu Medical College Teaching Hospital

Sinamangal, Kathmandu, Nepal

E-mail:deepmalla@yahoo.com and physical health can also be related through common risk factors, such as poor housing leading to both poor mental and poor physical health. Major understanding is needed of the relations between different mental disorders, between mental health and physical health, and on the developmental pathways of generic and disease-specific risk factors leading to mental ill-health².

Consultation-liaison psychiatry is over 50 years old. Its main goal has been to bring medicine and psychiatry closer together so as to improve patient care in its psychosocial and psychiatric aspects $^{3}$. Consultation-liaison is defined as provision of psychiatric services at the request of another health professional, often for physically ill patients in a non psychiatric hospital ${ }^{4}$. Problems of health and illness are inextricably related to physical as well as behavioral and environmental factors, each contributing to problems 
encountered in the medical management of patients. With current health care reimbursement conditions and recent research denoting the important relationship between mental health status and poor functioning, especially in medically ill patients, one would think that consultation-liaison (C-L) psychiatry would have an increasingly viable role in the outpatient health care sector ${ }^{5}$. Therefore, in context of our country as well the mental health problems are like an iceberg of disease. Even though they are referred by a medical person they hesitate to land up in a psychiatry clinic or visit a psychiatrist. Similarly, most of the health professionals themselves do not recognize depressive and anxiety symptoms and the need for referral'.

The main objective of this study was to assess the patterns of psychiatry morbidity in referred patients attending psychiatry out patient department (OPD) of Kathmandu Medical College and to help identify the socio demographic characteristics of the patients and pattern of referral from different department of the Kathmandu Medical College, to measure relationship between socio demographic profile, referral pattern and psychiatry illness and to compare the patterns of referral among the various departments of Kathmandu Medical College.

\section{METHODS}

This descriptive cross-sectional study was conducted in the department of psychiatry, after getting approval from the Institutional Review Committee at Kathmandu Medical College. The study population included all those patients referred from different OPDs from April to September 2014 for psychiatric evaluation to the department of psychiatry. All the patients who had given consent were only included in the study. Each patient underwent a detailed psychiatric evaluation by a consultant psychiatrist. Psychiatric diagnoses were considered as per ICD-10 criteria. Details of the patients including socio-demographic data, medical/ surgical diagnosis, psychiatric diagnosis and treatment were studied.

There were total 200 patients referred for psychiatric evaluation during the study period of six months. All of them were evaluated in detail once they were clinically stable. Socio-demographic details of patients, source of referral, medical/surgical and psychiatric diagnosis and psychiatric management done were tabulated and analyzed. SPSS software package version 16 was used to analyze the data. Descriptive statistics were used.

\section{RESULTS}

The maximum number of the patients were found to be in the age group 11-40 years; mean and median age was $37.26( \pm 1.86)$ and 35.5 respectively. There was a female predominance (66.5\%); the female: male ratio was 1.29:1. More than half of the study populations were married (67\%) and most of them came from nuclear families (62.5\%); one-quarter belonged to Brahmin caste and maximum were homemaker and agriculturist by occupation (Table 1). A majority of the patients were educated up to class seven (28\%) and most were from a middle socioeconomic status family (75\%).

\section{Table 1: Socio-demographic characteristics of the patients}

\begin{tabular}{|c|c|c|}
\hline $\begin{array}{l}\text { Socio Demographic } \\
\text { variables }\end{array}$ & $\begin{array}{l}\text { Frequency } \\
\text { (N) }\end{array}$ & $\begin{array}{c}\text { Percentage } \\
(\%)\end{array}$ \\
\hline \multicolumn{3}{|l|}{ Age } \\
\hline 10-20 years & 36 & 18.0 \\
\hline 21-30 years & 52 & 26 \\
\hline $31-40$ years & 46 & 23 \\
\hline $41-50$ years & 32 & 16 \\
\hline 51 years and above & 34 & 17 \\
\hline Total & 200 & 100 \\
\hline \multicolumn{3}{|l|}{ Sex } \\
\hline Male & 67 & 33.5 \\
\hline Female & 133 & 66.5 \\
\hline Total & 200 & 100 \\
\hline \multicolumn{3}{|l|}{ Marital Status } \\
\hline Single & 53 & 26.5 \\
\hline Married & 134 & 67 \\
\hline Divorced & 2 & 1 \\
\hline Widow & 4 & 2 \\
\hline Others & 7 & 3.5 \\
\hline Total & 200 & 100 \\
\hline \multicolumn{3}{|l|}{ Education } \\
\hline Illiterate & 53 & 26.5 \\
\hline Upto class 7 & 56 & 28 \\
\hline Class 8 to SLC & 42 & 21 \\
\hline Intermediate & 32 & 16 \\
\hline Graduate and above & 17 & 8.5 \\
\hline Total & 200 & 100 \\
\hline Socioeconomic status & & 23.5 \\
\hline Lower & 47 & 75 \\
\hline Middle & 150 & 1.5 \\
\hline Upper & 3 & 100 \\
\hline Total & 200 & \\
\hline \multicolumn{3}{|l|}{ Family type } \\
\hline Nuclear & 125 & 62.5 \\
\hline Joint & 65 & 32.5 \\
\hline Broken & 9 & 4.5 \\
\hline Others & 1 & 0.5 \\
\hline Total & 200 & 100 \\
\hline
\end{tabular}


Sixty percent of all patients were accompanied by their near relative during referral to psychiatry OPD. Frequency of referral was the highest from the medicine OPD (52\%) followed by ENT OPD (27.5\%).

Psychiatric evaluation was done once the referred patients were medically stable and the diagnosis was considered as per the ICD-10 criteria. The most common chief complaints during referral were headache (18.5\%), disturbed sleep (17\%) and more than three sites with pain symptoms (17\%). Others complaints included foreign body sensation in the throat (16.5\%), excessive fearfulness (15.5\%) and alcohol related problems (4.5\%). A majority of $65.5 \%$ patients did not have any co morbid physical illness. $75 \%$ patients were referred with no psychiatric diagnosis where as the most common diagnosis made by the referred departments was generalized anxiety disorder (GAD) (11\%).

Sixteen percent of referred patients had already been prescribed an antidepressant by other departments before reaching the psychiatry out patient department.

Almost half (49\%) of the patients were found to have depressive illness (including dysthymia and adjustment disorder); followed by anxiety (35.5\%) and dissociative disorder/ conversion disorder (5.5\%). (4.5\%) had alcoholrelated problems (dependence/ withdrawal).

More than half (55\%) of the referred patients believed that they were suffering from some sort of neurological

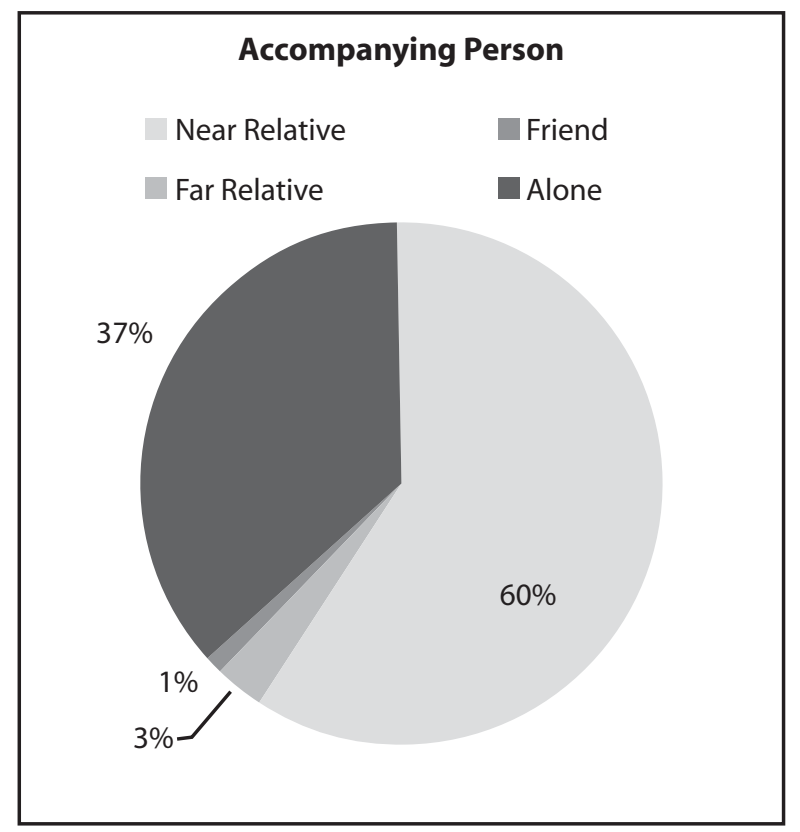

Figure 1: Accompanying person with the patient in OPD

illness. Most of the patients (64.5\%) were referred on the same day by other departments followed by $21.5 \%$ in more than a month, $8 \%$ within a week and only $6 \%$ between a period of one week to one month.

$36 \%$ of the patients had also sought alternative treatment before coming to the psychiatry out patient department in the form of visiting a traditional faith healer (52\%) or using ayurvedic treatments (17\%).

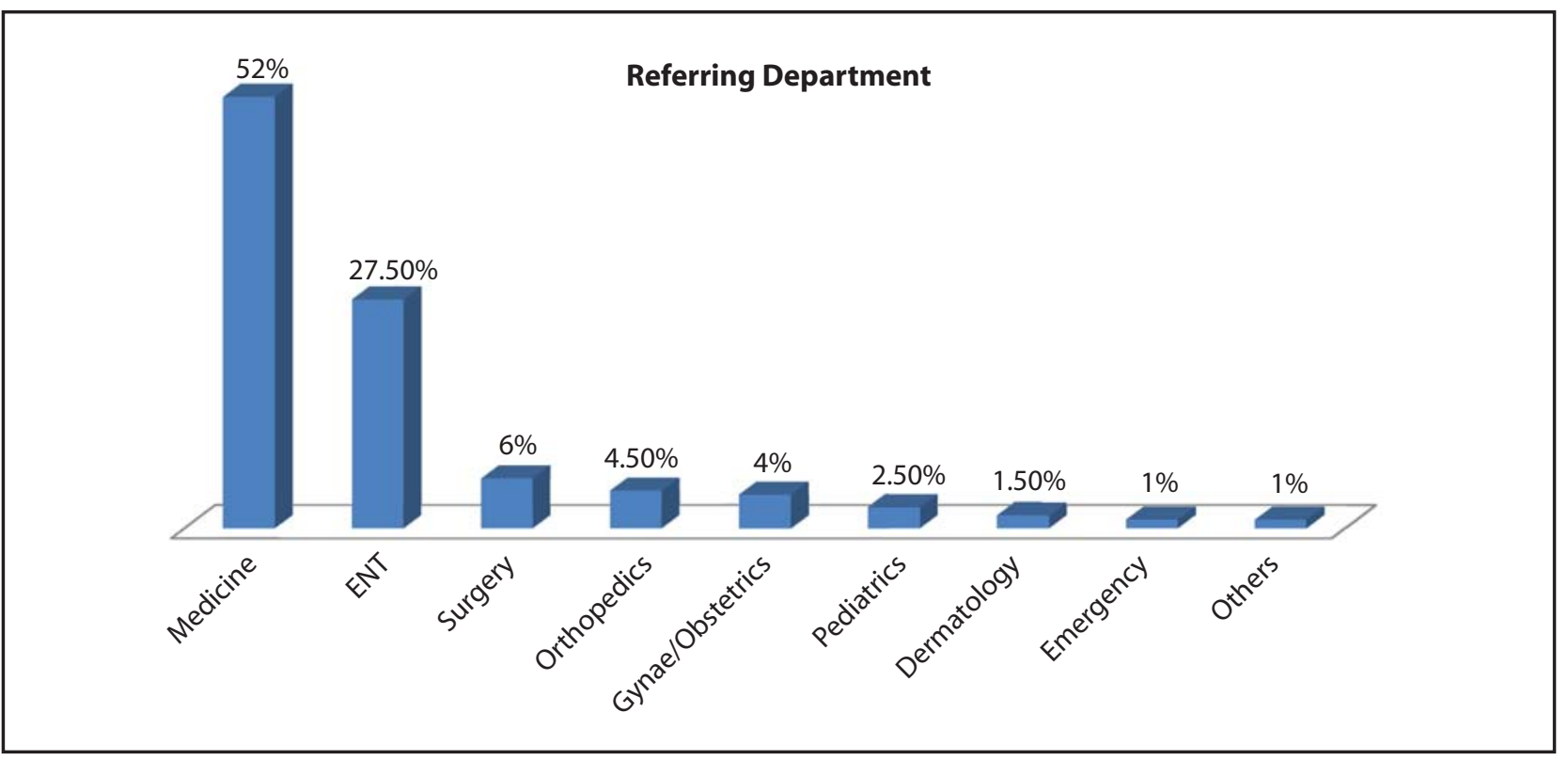

Figure 2: Various referring departments 


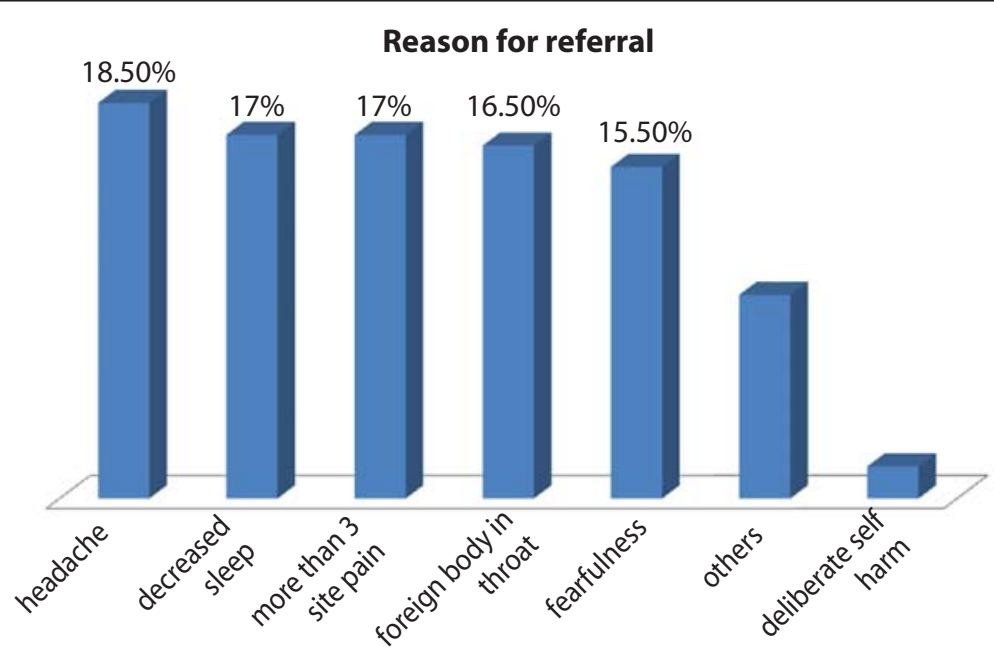

Figure 3: Reasons for referral to psychiatry department

\section{Comorbid physical illness}

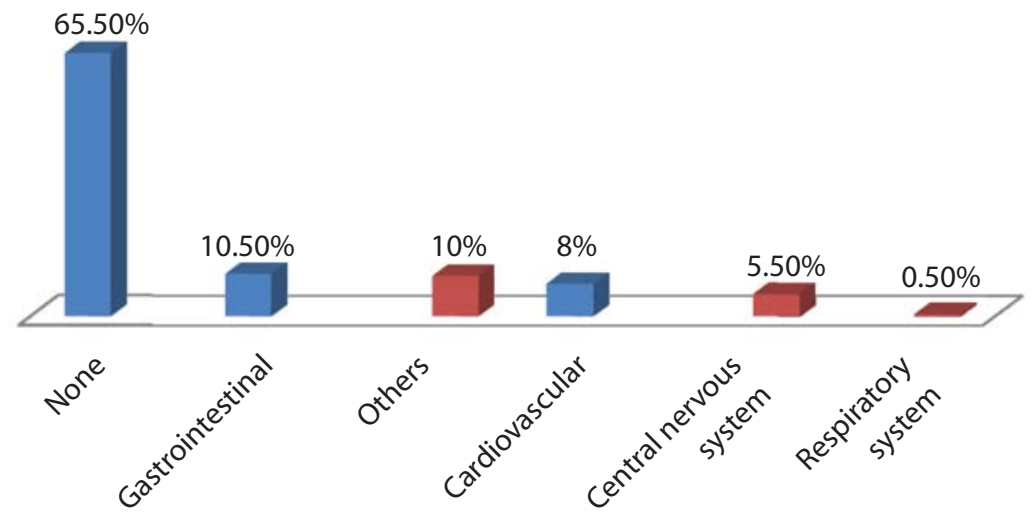

Figure 4: Co-morbid physical illnesses of the patients

\section{Final Diagnosis}

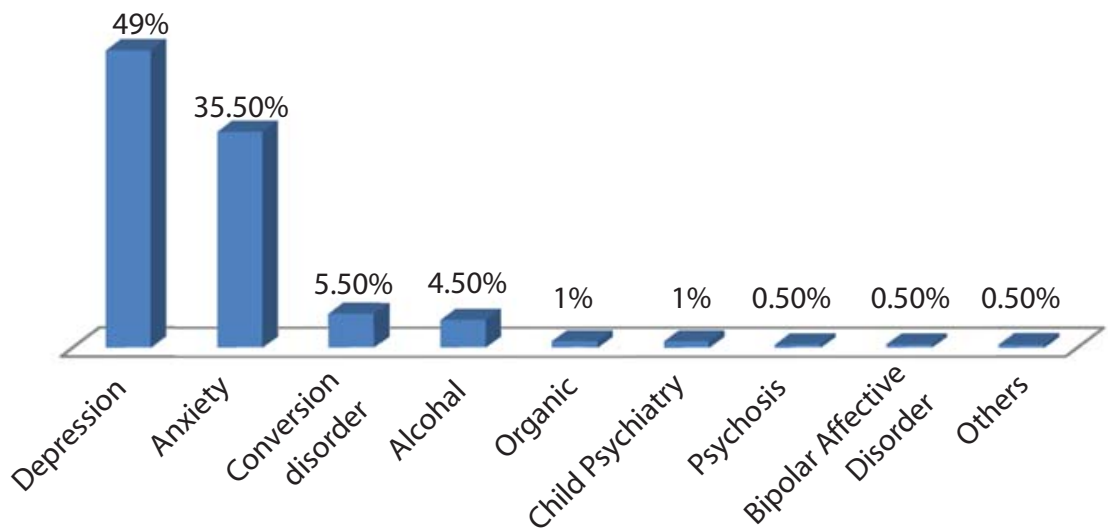

Figure 5: Psychiatry diagnosis of the patient 


\section{Duration of referral}

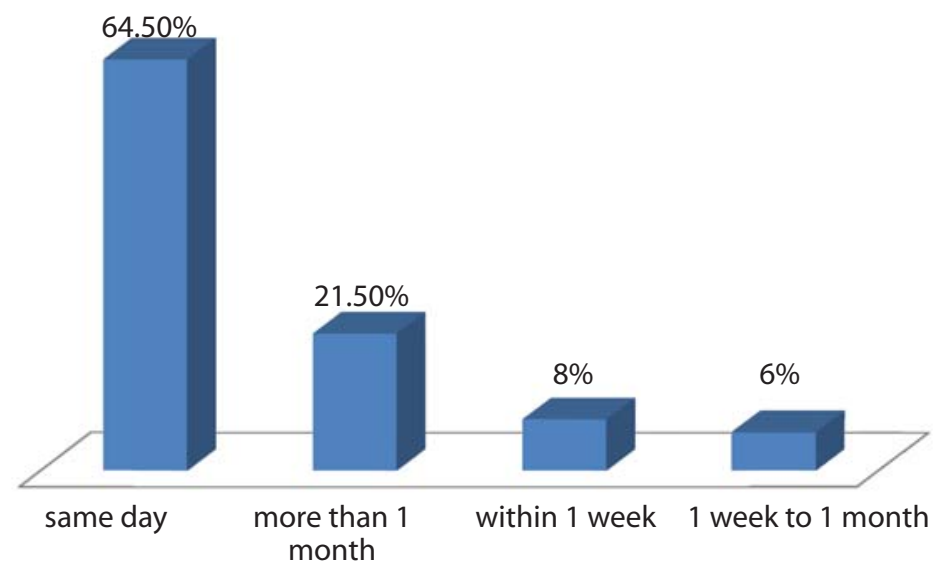

Figure 6: Duration of referral to psychiatry department

\section{DISCUSSION}

Psychiatric morbidity is quite common among patients suffering from various medical or surgical illnesses. Studies have shown that a substantial proportion of psychiatric morbidity in medical and surgical patients remain unrecognized, leading to low rate of psychiatric referral ${ }^{2}$. The psychiatric co morbidity with physical illness alters the course and outcome of both conditions and therefore timely psychiatric referral and management assumes paramount importance as this approach will prevent unnecessary wastage of time and resources.

Keeping these facts in mind, in order to initiate an attempt to understand the factors affecting the practices of consultation-liaison psychiatry, we evaluated the patients referred for psychiatric evaluation from different out patient departments in our hospital and tried to analyze the interrelationship between them and their primary source of referral; in addition to the descriptive analysis of the socio-demographic profile and treatment related factors of those patients.

The study revealed that the maximum numbers of patients were in their second to the fourth decades of life, females, housewives and married; keeping with the findings from earlier similar studies done ${ }^{3,4,5,6}$. More than half of the patients were referred from the medical out patient department (52\%) which is in keeping with the findings from a Kathmandu based medical college study ${ }^{7}$. Other departments included ENT (27.5\%) and surgery (6\%). A recent research conducted in India looking into the psychiatric referral patterns also revealed more than $50 \%$ referrals were from general medicine ${ }^{8,9}$.
In our study, depressive disorder was found to be the most common diagnosis (49\%) among the patients referred to the Psychiatry department. Depression is strongly related with ischemic heart disease, heart failure and myocardial infarction ${ }^{10,11}$. A study done at Patan hospital, there were 120 psychiatric referrals. The majority of referral was from department of medicine and depression was the most common finding as in our study. These findings are similar to previous studies done ${ }^{12,13}$. Out-patient studies in the west report a prevalence of $12-36 \%$ of psychiatric illness in patients ${ }^{12}$. Indians studies carried out on outpatients report figures varying from $33.4 \%$ to $54 \%{ }^{14,15}$. The reason for depression being the most common diagnosis could be because most patients tend to present with vague somatic symptoms instead of expressing their low mood especially in a developing country like Nepal. Anxiety disorder remains the second most common diagnosis in our study similar to other studies conducted in medical colleges in $\mathrm{Nepal}^{7}$. Probable reason for this could be that the patients with anxiety tend to report various physical symptoms and consult other departments before being referred to psychiatry.

In our study the most referring department was from medicine which is similar to a study done in India ${ }^{16}$. Mostly female patients were referred for psychiatric consultation than male patients. Similar findings have been reported elsewhere ${ }^{17,18,19,20,21}$. The greater prevalence of female patients referred for psychiatric evaluation in our study can be explained by the fact that females are more prone for mental illness ${ }^{1}$. The most common reasons for referral to the psychiatry out 
patient department in our study were complaints of having severe headaches (18.5\%), disturbance in sleep (17\%) pattern followed by having pain in more than three sites of the body (17\%). Other studies showed different reasons for referral such as abnormal behavior, irrelevant talk and suicidal attempt ${ }^{7,9}$.

This difference in reasons for referral could be explained by differences in complaints seen in out patient department patients, who present with mild symptoms compared to in patient department patients who present with severe symptoms and require admission in the ward. Another reason for this difference could be explained by various studies taking different types of reasons of referral into account instead of basic chief complaints addressed in this study. More than half of the referred patients perceived that they were suffering from some sort of neurological illness whereas very few recognized it to be related to any mental illness. This could be explained by the common perception of a layman's view regarding any pain symptom to be caused due to "nasha ko samasya" (nerve problem) or any anxiety symptom such as palpitations classified as "pressure high" or "gastric."

In a pathway to care study conducted in central India a study showed the majority of patients (69\%) had first contacted faith healers and a qualified psychiatrist was the first contacted person for only $9.2 \%$ of the patients ${ }^{22}$. However in a similar study conducted in the same institution where this study was conducted; the study

\section{REFERENCES}

1. Saraceno B.Prevention of mental disorders, effective interventions and policy options summary report. World Health Organization, department of mental health and substance abuse in collaboration with the prevention research Centre of the universities of Nijmegen and Maastricht.

2. Nabaro J. Unrecognized psychiatrtic illness in medical patients. Brit Med J 1984; 289 : 635-6.

3. Doongaji DR, Nadkarni RP, Bhatawdekar ML. Psychiatric referrals in two general hospitals. J Postgrad Med[serial online] 1989 [cited 2014 nov 1];35:171. Available from: URL:http://www.jpgmonline.com/text. asp?1989/35/3/171/5694.

4. Brown A, Cooper AF. The impact of a liaison psychiatry service on patterns of referral in a general hospital. British Journal of Psychiatry. 1987;150:837. showed that a total of $64.8 \%$ visited psychiatrists first and $35.2 \%$ visited faith healers ${ }^{23}$. Our study also showed similar results where a few patients (36\%) seeking help from a traditional faith healer or opting for ayurvedic treatment before being referred to the psychiatric out patient department. This depicts the poor awareness of mental health problems among the population.

However our study has limitations. We have not used standardized instruments like structured interview schedules, rating scales to assess for multiple psychiatric diagnoses and severity of psychiatric illness. Also we recruited patients on consecutive basis instead of using any sampling technique for the same.

\section{CONCLUSION}

More than half (52\%) referrals were from medical ward coming with the chief complaint of headache $(18.5 \%)$ followed by disturbance in sleep pattern (17\%). The most common psychiatric diagnosis was depression (49\%) followed by anxiety (35.5\%). The co-occurrence of medical and psychological/psychiatric conditions is common, which demands timely identification and early interventions in order to reduce morbidity and mortality. Most of the patients are unaware of their psychiatric illness and they visit other medical out patient departments for their symptoms. The health care workers are also not very much trained or aware of psychiatric symptoms which usually cause psychiatric patients to be unrecognized and treated as a medical illness.

5. Lipowski ZJ, Wolston EJ. Liaison psychiatry: referral patterns and their stability over time. American Journal of Psychiatry. 1981;138:1608-11.

6. Risal A, Sharma PP. Psychiatric manifestations of patients admitted for intentional self harm. Journal of Institute of Medicine. 2011;33(1):43-8.

7. Singh PM, Vaidya L, Shrestha DM, Tajhya R, Shakya S. Consultation liaison psychiatry at Nepal Medical College and Teaching Hospital. Nepal Med Coll J. 2009;11(4):272-4.

8. Parkar SR, Sawant NS. Liaison psychiatry and Indian research. Indian J Psychiatry. 2010;52(7):386-8.

9. Jhanjee A, Kumar P, Srivastava S, Bhatia M. S. A Descriptive Study of Referral Pattern in Department of Psychiatry of A Tertiary Care Hospital of North India. Delhi Psychiatry Journal 2011; 14:(1)

10. Rugulies R. Depression as a predictor for cardiac disease. A review and meta-analysis. Amer J Preventative Med 2002; 23 : 51-61. 
11. Van der Kooy K, Van Hout H, Marwijk H, Marten $H$, Stehouwer C, Beekman A. Depression and the risk for cardiovascular diseases. Systematic review and meta-analysis. Int'I J Geriatric Psychiatr 2007; 22 : 613-26.

12. Chakrabarti K. A study of Psychiatric Referral in Patan Hospital. Souvenir of the 1st Conference of PAN, BPKIHS, Dharan, Nov.,1999; 13-14.

13. Bourgeois JA, Wegelin JA, Servis ME, Hales RE. Psychiatric Diagnoses of 901 Inpatients Seen by Consultation-Liason Psychiatrirst at an Academic Medical Center in a Managed Care Enviroment. Psychosomatics 2005; 46 : 47-57.

14. Rodin G, Voshart K. Depression in the medically ill: an overview, Amer. J. Psychiatr., 1986; 143 : 696-705.

15. Murthy RS, Kuruvilla K, Verghese A, Pulimood BM. Psychiatric illness at general hospital medical clinic. J. Ind. Med. Assoc 1976; 66 : 6-8.

16. Srirain TG, Shamsunder C, Mohan KS, Shanmugam V. Psychiatric morbidity in the medical outpatients of a general hospital. Ind. J. Psychiatr 1986; 28 : 325328.
17. Dhavale HS, Barve RG. J Postgrad Med. 1990; 36 : 199-202.

18. Anstee $\mathrm{BH}$. The pattern of psychiatric referrals in a general hospital. Brit. J. Psychiatr 1972; 120 : 631634.

19. Little JC. In, "Psychiatry in a general hospital", Butterworth and Co. Ltd., London 1974; pp. 9- 46

20. Poynton AM. Psychiatric liason referrals of elderly in-patients in a teaching hospital. Brit. J. Psychiatr 1988; $152: 45-47$.

21. Zuo C, Yang L, Chu CC. Patterns of psychiatric consultation in a Chinese general hospital. Amer. J. Psychiatr 1985; 142 : 1092-1094.

22. Lahariya C, Singhal S, Gupta S, and Mishra A. Pathway of care among psychiatric patients attending a mental health institution in central India. Indian J Psychiatry 2010 Oct-Dec; 52(4): 333-338.

23. Pradhan SN, Sharma SC, Malla DP, Sharma R. A study of help seeking behavior in psychiatric patients. Journal of Kathmandu Medical College 2013; 2(1). 